\title{
The Use of Cohesive Devices to Provide Coherence in Argumentative Essays of Universitas Negeri Semarang Graduate Students
}

\author{
Bahya Alfitri ${ }^{\varpi}$, Issy Yuliasri \\ Universitas Negeri Semarang, Indonesia
}

\begin{abstract}
Article Info
Article History:

Recived 09 April 2021

Accepted 14 June2021

Published 15

September 2021

Keywords:

Cohesive devices,

coherence, chain

interaction, cohesive

harmony,

argumentative essays

Abstract

This study aims to analyze the use of cohesive devices and the chain interaction of cohesive devices to achieve coherence in argumentative essays of Universitas Negeri Semarang graduate students. This study employed descriptive qualitative research design. It focused on cohesion and coherence analysis of students' writing. The findings of the study showed that all of the types of cohesive devices such as reference, substitution, ellipsis, and reiteration were found in the students' essays. These cohesive devices provide the coherence of the text through their semantic relation or bound which create the two cohesive chains; identity chains and similarity chains. The interaction between both chains can give explicit signals to guide readers towards the intended interpretation of the text. The result of this chain interaction is known as cohesive harmony. Most of students' essays achieve coherence because the total tokens of the students' essays enter more than $50 \%$ of chain interaction. Unfortunately, the students overuse certain types of cohesive devices such as repetition in creating the chains.
\end{abstract}

${ }^{\circledR}$ Correspondence Address :

Kampus Pascasarjana Unnes, J1. Kelud Utara III Semarang

p-ISSN 2087-0108

50237, Indonesia

e-ISSN 2502-4566

E-mail : bahyaalfitri355@gmail.com 


\section{INTRODUCTION}

Writing is a productive skill that can show the students' high-level thinking. In Asia, English writing becomes one of the important goals of English education reform (Lie, 2019). It becomes the most essential activity for measuring students' achievement, especially in the case of tertiary level students. They are required to be able to make good academic writing text such as an argumentative essay. This is a complicated assignment that must be carried out with the highest ability because the students do not only focus on the grammatical aspect of the writing, but also on the purpose of writing a text (Khunaifi, 2015). The text has been created for a communicative purpose (Widdowson, 2007). There is communication between writer and reader in the text (Fitriati \& Yonata, 2017). Therefore, the writers have to make their text united and meaningful, so that the readers can grasp the writer's idea easily.

There are some features to create good writing text. Some of them are cohesion and coherence. Murcia and Olshtain (2000) state that both cohesion and coherence are important to produce good writing. They give contribution to the maintenance of unity in the paragraphs of writing. There is an important distinction between them. The presence of cohesion constructs the internal coherence of text (Eggins, 2004; Halliday \& Hasan, 1976). It is laid as the foundation of coherence (Halliday \& Hasan, 1989). Cohesion links one part of a text to another and gives a sequence of sentences. It comes from cohesive devices such as reference, substitution, ellipsis, and reiteration. They have a role in the text to predispose the reader to find the coherence and the last to interpret the message. Cohesion enables readers to understand or perceive the semantic relationships existing within and between the sentences (Shabani et al., 2015). Coherence, on the other hand, is the appropriateness of the occurrence of contextual text that makes the sense of message in the text conveyed. A text is said as coherent if the readers can follow each clause without losing the meaning (Hellalet, 2013). This coherence is provided by cohesion. Halliday and Hasan especially Hasan $(1984,1989)$ claims that the perceived coherence in the text depends on the interaction of cohesive devices called cohesive harmony. Cohesive harmony is achieved when it brings together grammatical and lexical cohesive devices into certain kinds of semantic relation or bound, subjecting them to semantic considerations of identity and similarity chain. It is also harmonious because of the output of the textual function in the form of the cohesive chain and its interactions.

Writing which does not have cohesion and coherence may not be easily understood. However, it may not be easy for the students to use cohesive devices properly and make the text more coherent. Based on the preliminary research on some graduate students of a university in Indonesia, it can be concluded that even at the graduate level students still face difficulties in creating cohesive and coherent texts. The students used a lot of cohesive devices but some of them were used inappropriately. It can affect the coherence of the texts.

Several studies focusing on analyzing cohesion and coherence have been conducted by some researchers. Amperawaty and Warsono (2019) conducted the research to find cohesion and coherence devices. The result shows that reference is the dominant type of cohesive devices. Saud (2015) found English students in Saudi face the difficulties to construct a coherence text in their writing academic. Demantik (2008) conducted the research on cohesive harmony in Jakarta post. He found some types of cohesive devices which provide identity chains and similarity chains. This finding also supports the idea of Tilney (2018), who also conducted a study on cohesive harmony in short story. The result shows that the text is lack of coherence because it cannot hold together all the chains of meaning. The finding of Chiaoi (2019) also matches with the finding of the study. He found five identity chains that are provided by reference in filmic text. This cohesive chain run through texts and provides them with the links to create texture in the text (Taboada, 2019). 
This study is different from the previous studies because it analyzes the use of cohesive devices to provide coherence in argumentative essays. Specifically, this study aims to answer two major research questions. The first is related to the use of cohesive devices to provide coherence in argumentative essays of Universitas Negeri Semarang graduate students. The second is related to chain interactions of cohesive devices achieving coherence in their essays.

\section{METHODS}

This qualitative study with descriptive research design seeks the answer how cohesive and the chain interactions of cohesive devices achieve coherence in argumentative essays of Universitas Negeri Semarang graduate students.

The source of data was taken from the assignment project of the first semester of English graduate students. After reading the text, the researcher took six essays purposively. The analysis of the data was started by classifying cohesive devices based on their types such as reference, substitution, ellipses, and reiteration. It is also used to see the semantic relation of cohesive devices. The finding of cohesive devices and the chain interaction were presented in figures which then were counted. It is used to see the proportion of the text participates in such chain interaction. Here, all of the tokens in the text must be counted. Some text was coherent because the tokens achieved more than $50 \%$ of central tokens.

\section{RESULTS AND DISCUSSIONS}

The analysis of argumentative essays of Universitas Negeri Semarang graduate students revealed that the most prominent cohesive devices that provide coherence were reiteration. Other kinds of cohesive devices were used less frequently. The occurrences and percentage of reference, substitution, ellipses, and reiteration to provide coherence are presented in the Table 1.
Table1. The percentage of cohesive devices in argumentative essays of Universitas Negeri Semarang graduate students.

\begin{tabular}{llllll}
\hline $\begin{array}{l}\text { Cohesive } \\
\text { devices }\end{array}$ & $\begin{array}{l}\text { Total of } \% \\
\text { tokens }\end{array}$ & $\begin{array}{l}\text { Total of } \% \\
\text { cohesive } \\
\text { chains }\end{array}$ \\
\cline { 1 - 2 } \cline { 4 - 5 } Reference & 214 & 20.40 & 28 & 10.18 \\
Substitution & 2 & 0.19 & 1 & 0.36 \\
Ellipsis & 2 & 0.19 & 1 & 0.36 \\
Reiteration & 831 & 79.21 & 245 & 89.09 \\
Repetition & 694 & & 165 & \\
Synonym & 34 & & 16 & \\
Antonym & 98 & & 47 & \\
Hyponymy & 38 & & 14 & \\
Meronymy & 12 & & 3 & \\
\hline
\end{tabular}

The use of reiteration holds the highest frequency that is used to provide coherence in students' essays. There were 831 tokens or $79.21 \%$ out of the 1049 tokens of data and it also provided 245 chains. Most of them are in the form of repetitions. While the second cohesive device holds by reference that provided 214 tokens or $20.40 \%$ and it provided 28 chains. Meanwhile, Ellipsis and substitution are the least prominently, each of them only provided 2 tokens or $0.19 \%$ of cohesive devices and 1 cohesive chain.

The use of reference to provide coherence in argumentative essays of Universitas Negeri Semarang graduate students

Based on the finding, it can be identified that the students used all of the types of references in their essays such as personal reference, demonstrative reference, and comparative reference. Reference is used to signal retrieval (Halliday \& Hasan, 1976). It is an important element that can introduce the participants and keeps track of them in the text. Thus, it becomes the second prominent cohesive device that provides coherence in students' essays. It implied that the students were more familiar with the type of reference and more used it to create cohesion 
by creating a link between the element (Halliday \& Matthiessen, 2014). This finding also confirms the study that was conducted by DontchevaNavratilova et al (2017). They investigated the use of coherence and cohesion in newspaper discourse. Base on their findings, the category of reference usually becomes prominent since it is necessary to refer repeatedly to things or people mentioned through the discourse.

Reference provides the tie of tokens and identity chain. The connections between the tokens, which say as bonds play a key role in discourse coherence, the semantic bonds or semantic relation co-reference that found in essays create some identity chains. It confirms the theory proposed by Halliday and Hasan (1989) who said that the presence of a cohesive device and its relation of semantic items provide coherence by creating the ties of tokens and chain in the text. The example is given as follows:

Example:

"For workers, great mobility supports the effectiveness and efficiency of their work (E1.C2). They can go to the workplace easily without spending too much time (E1.C3)"

Based on this example, there is semantic relation that occurs between the members of the tie co-referentiality that realized by the device of identity reference. It is because they refer to the same people in the text. Co-referential relation which provides the texture occurs between the references their-they to workers. They are a kind of personal reference which the tokens of their and they refer back to token workers. They create an identity chain because all the links in the chain refer to the same entity. The identity chain in this essay is workers-their-they. The members of this identity chain can give explicit signals to guide the reader towards the intended interpretation of the text which is the foundation for coherence. The presence of lexical token reference which creates a tie and linking chain in the text contributes to text coherence (Halliday \& Hasan, 1989).

The identity chains are the indication of tight coherence within the text and that chain interaction is a strong basis in determining text coherence. Reference provided some identity chains in achieving coherence in argumentative essays of Universitas Negeri Semarang graduate students. This chain is used to examine coherence by seeing the chain interaction between this identity chain and other chains.

The use of substitution to provide coherence in argumentative essays of Universitas Negeri Semarang graduate students

The next type of cohesive device that is described in this research is substitution. The goal of substitution is not to change the meaning but mention the previous items by another, by its substitute. Therefore, the use of substitutions is mostly in the form of anaphoric type. The presence of substitution and its relation of semantic items contribute to text coherence by creating ties of tokens and similarity chains in essays. This matches the theory proposed by Halliday and Hasan (1989) who said that the presence of a cohesive device and its relation of semantic items provide coherence by creating the ties of tokens and chain in the text. The example is given bellow:

Example:

"Another reason is the weak policies in Indonesia (E1.C38) that can urge people to use mass transportation instead of the private one (E1.C39)"

This example is a type of nominal substitution that enables us to substitute one word with another by using the substitute one/ones. In this clause, the word one stands for transportation. It means transportation is substituted by the word one. The substitution one has a function as the head of a nominal group which can substitute one word; transportation. It does not refer to the same transportation in the previous situation but refers to other transportation. The semantic relation that ties two tokens in this data is co-classification which the private one and transportation refer to an identical class. This co-classification relation gives signal from the anaphoric item the private one in the second clause which is interpreted by substitution that has already been mentioned as transportation. Thus, the substitution that occurs in this essay creates similarity chains of coclassification. There is only 1 similarity chain 
formed by substitution cohesive devices. It is transportation - the private one. This similarity chain goes a long way towards building the foundation for coherence because it gives the signal to guide the reader to interpret the text.

Unfortunately, the use of substitution becomes the lowest prominently used among cohesive devices in students' essays.

This finding confirms the result of other researchers in some cases. Rahman's (2013) study, which investigated the descriptive writing written by Omani student-teacher, indicated that student-teacher lack the repertoire of substitution. Suwandi (2016) revealed that the two aspects of substitution and ellipsis are underused by the students in writing. According to Halliday and Hasan (1976), substitution and ellipsis are used more in speaking than writing. While the students write argumentative essays which is a kind of academic writing. For this reason, the students are not frequently using substitution device.

The use of ellipsis to provide coherence in argumentative essays of Universitas Negeri Semarang graduate students

The next finding of cohesive devices is ellipsis. Ellipsis is the omission of an item, but it still can be understood (Halliday \& Hasan, 1976). It means that in certain contexts, it is possible to omit some item of word or phrase rather than repeating it, but it is still understood to be in the sentence. The presence of ellipsis and its relation of semantic items provide text coherence by creating ties of tokens and similarity chain in students' essays. This matches the theory proposed by Halliday and Hasan (1989) who said that the presence of a cohesive device provides coherence by creating the ties of tokens and chain in the text. The example is given bellow:

Example:

"It will be easy for students who have a family in the same city with their university (E5.C2) because they can stay at their family's house (E5.C3) but for those who don't [O: have a family] (E5.C4) they have to find their new house (E5.C7)"

The ellipsis that occurs in this essay is verbal word don't. The token have a family in the negative form is omitted by token don't in the next clause instead of writing don't have a family. It is creates a similarity chain which is related by semantic relation of tie co-classification.

The members of the similarity chain are have a family and don't. This chain can build the foundation of coherence because it gives the signal to guide the reader to interpret the text. The presence of lexical token ellipsis which creates a tie and linking chain in the text contributes to text coherence (Halliday \& Hasan, 1989).

However, the use of ellipsis becomes the least prominent type in students' essays. This confirms the finding of previous research by Adiantika (2015) who emphasized that substitution and ellipsis are the kinds of the cohesive device which is underused by the students in writing. Karadeniz (2017) also conducted the research to determine the relationship between faculty of education students' levels of using cohesive devices and its coherence. The result indicated that there was no significant statistical ellipsis found in the students' writing. The ellipsis and substitution are more commonly used in oral communication (Halliday \& Hasan 1976).

\section{The use of reiteration to provide coherence in argumentative essays of Universitas Negeri Semarang graduate students \\ This part focus on the discussion of} reiteration provides coherence in students' argumentative essays. The results of this research indicate that the most contribution of coherence is provided by reiteration. It ensures topic continuity and activates relevant discourse processing knowledge. It provides the tie of tokens and similarity chains. This analysis supports the theory proposed by Halliday and Hasan (1989) who said that the presence of a cohesive device and its relation of semantic items provide coherence by creating the ties of tokens and chain in the text. The members of this similarity chain achieved chain interaction that can give the explicit signals to guide the reader towards the intended interpretation of the text. The example can be seen bellow:

\section{Example:}


"By using MRT, the time to get the destination will be faster than using other vehicles (E6.C25) For example, if using $M R T$ as a transportation to Bundaran HI from Lebak Bulus (E6.26) it is only 15-20 minutes (E6.27)"

Based on this example, it can be seen there are repetitions of lexical tokens $M R T$ and using. The students tend to repeat the same term. The lexical token $M R T$ refer back to another lexical token $M R T$ that has been mentioned in the previous clause. The lexical token using also appears many times with the morphologically distinct forms of the same lexical unit. The repetition that occurs in this essay creates a similarity chain that is related to the semantic relation of tie co-extension. The member of the similarity chain occurs between using and $M R T$. The token of lexical item $M R T$ creates a similarity chain MRT-MRT-MRT, while the token of lexical item using create a similarity chain using-usingusing-use-used. This chain is used to examine coherence by seeing the chain interaction between this identity chain and other chains.

These findings confirms Tilney's (2018) findings that the continuum of interaction was reflected in his data when he investigated cohesive harmony in the short story. He found some types of reiteration which provide similarity chains. The similarity chains in the short story are the indication of tight coherence within the text and that chain interaction is a strong basis in determining text coherence. Lexical chaining features are useful for predicting discourse coherence quality (Somasundaran et al., 2014). Their analysis also indicated that lexical chaining features can improve performance on various genres of writing by different populations of writers.

This similarity chain especially the chain created from repetition has a high frequency of occurrence in students' essays. While other kinds of reiteration such as synonymy, antonymy, hyponymy, and meronymy were underrepresented. These results are parallel with the results presented by Kafes (2012) and also Qudah (2016) who emphasized that lexical cohesion, specifically repetition, was predominantly used by students in their English written essays. The result of the study showed that graduate students seem to find the use of repetition a convenient way to establish lexical ties. One of probable reasons is to create emphasis on the topic.

Unfortunately, the number of repetitions in this current study becomes an indication that the students overuse repetition in creating the similarity chain. The example is given as follows: Example:

"Long time ago, people ate food that was very good for them (E3.C1). They ate food that not contains chemicals, preservatives, artificial colors, and flavors (E3.C2). The people also spent a lot of time to cooks their own foods (E3.C3). Therefore, those people were not affected by food (E3.C4) that they ate (E3.C5), because all the foods that they had was natural and healthy (E3.C6)"

This example showed that the lexical tokens eat and foods were mentioned many times in every clause. The students prefer to repeat the same word rather than use another type of reiteration to emphasize the topic.

The overuse of certain cohesive devices by the students can lead to boredom to the readers and redundancy in their writing. Hinkel (2001) argued that the students tend to use cohesive devices such as repetition to reveal the tension of the writer. Thus, as graduate students, they may be aware they have to emphasize the point of the topic that is why they tend to overuse repetition.

The chain interaction of cohesive devices achieving coherence in argumentative essay of Universitas Negeri Semarang graduate students.

Cohesion and coherence are two elements that have a relation to each other. Cohesion gives an important contribution to our sense of coherence in a text. According to Halliday and Hasan (1989) cohesion contributes to create coherence in the text; it is laid as the foundation of coherence. The cohesive device and coherence can be measure through cohesive harmony analysis (Lee, 2018). Halliday and Hasan (1989) claims the perceived coherence in the text depends on the chain interaction of cohesive devices called cohesive harmony. It is known as harmony when it brings together grammatical and lexical cohesive devices into 
certain kinds of semantic relation or bound, subjecting them to semantic considerations of identity and similarity chain. It is also harmonious because of the output of the textual function in the form of the cohesive chain and its interactions.

Although the chains build the foundation for coherence, they are not sufficient; it is needed to include some relations that are characteristic of those between the components of a message. This is the relation of chain interaction. The relation of chain interaction occurs in the interaction of identity chain and similarity chain. This analysis supports the theory proposed by Halliday and Hasan (1989). A minimum requirement for chain interaction is at least two members of a chain should stand in the same relation to two members of another chain.

In examining the chain and chain interaction in a text, Halliday and Hasan especially Hasan $(1984,1989)$ suggested for placing the interaction in the perspective of the total text, it is used to see the proportion of the text participates in such chain interaction. Here, all of the tokens in the text must be counted. A token itself is a lexical item which carries the content. Some of tokens are then assigned to chains. The tokens in the text which are not subsumed in chain is called as peripheral tokens (PT), all tokens that enter into identity or similarity chains are called relevant tokens (RT). The relevant tokens that interact each other are described as central tokens (CT). While TT is the total tokens that are provided by cohesive devices.

Furthermore, the results of the interaction chain in argumentative essays of Universitas Negeri Semarang graduate students are presented in Table 2.

Table 2. The result of chain interaction

\begin{tabular}{llllll}
\hline Essay & TT & RT & PT & CT & $\begin{array}{l}\text { CT as \% of } \\
\text { TT }\end{array}$ \\
\hline 1 & 228 & 154 & 74 & 121 & 53.07 \\
2 & 326 & 240 & 86 & 172 & 52.76 \\
3 & 165 & 135 & 30 & 79 & 47.87 \\
4 & 249 & 198 & 51 & 135 & 54.21 \\
5 & 203 & 146 & 57 & 120 & 59.12 \\
6 & 206 & 178 & 28 & 103 & 50 \\
\hline
\end{tabular}

Hasan (1984) proposes that examining chain interaction is useful for analyzing the qualities of the texts. She introduces the nation of cohesive harmony as one of the ways to judge the degree of text coherence. Hasan's concept, cohesive harmony can be measured from the percentage of central tokens, that is, tokens that enter in chain interaction. The text will be coherent if it has more than $50 \%$ central tokens. The last column represents the degree of cohesive harmony in these texts.

The result of the table 2 shows that not all the total tokens of students' essays enter $50 \%$ of chain interaction. Only essays 1, 2, 4, 5, and 6 achieve that. The tokens which involved in chain interaction are called central tokens. These central tokens are mostly found in essays $1,2,4$, 5 , and 6 . They have more than $50 \%$ central tokens. These essays involve a large number of cohesive chains which many of them interact with other chains. Thus, essay 1, 2, 4, 5, and 6 are judged more coherence. While the total tokens of essay 3 only achieve $47.87 \%$ of chain interaction. It involves a large number of cohesive chains but many of these chains are not interact with other chains. Thus, essay 3 is less coherent than others. In this current research the example can be seen when we take the interaction of identity chain and similarity chain.

Example:

" The Indonesian government provides public transportation as an attempt to reduce traffic jam (E1.C20). This is supported by Yudhistira et al (2016) concluding that (E1.C21) if there is no improvement in public transportation (E1.C22), the use of private vehicle will increase traffic jam (E1.C23)"

Based on this example, it can be found some tokens that include to cohesive devices, but not all tokens can interact with other tokens. The interaction token in these clauses can be seen from the tokens public transportation and private transportation; both of them form a similarity chain since the relationships between these items are co-extension; antonym. The tokens reduceincrease and traffic jam-traffic jam also form two similarity chains since the relationships between these items are co-extension; antonym and 
synonym. All of these chains interact each other that can be seen in Figure 1.

\begin{tabular}{|l|r|r|l|l|}
\hline $\begin{array}{l}\text { C20public } \\
\text { transportation } \\
\text { C23private } \\
\text { transportation }\end{array}$ & C20Reduce & C23increase & $\leftrightarrow$ & $\begin{array}{l}\text { C20Traffic } \\
\text { jam }\end{array}$ \\
& i & C23Traffic \\
ii & jam \\
\hline
\end{tabular}

Figure 1. The chain interaction

The figure 1 shows that members of the complex chain 1 interact with the members of chain 2 and the members of chain 2 interact with the member of chain 3 . It can be seen that the token public transportation in similarity chain 1 interact with reduce in similarity chain 2 . The interaction between them is called 'actor-action' relation. This interaction is also the same with the interaction between tokens private transportation and increase. While the interaction of first and second token of reduce and increase in similarity chain 2 interact with traffic jams in similarity chain 3 ; the token reduce in similarity chain 2 interact with traffic jam in similarity chain 3. The interaction between them is called 'action-acted upon relation'. This interaction is also the same with the interaction between tokens increase and traffic jam.

\section{CONCLUSIONS}

All of the types of cohesive devices are found in argumentative essays of Universitas Negeri Semarang graduate students. These cohesive devices provide coherence of the text through their semantic relation or bound which create the two cohesive chains; identity chains and similarity chains. The interaction between both of chains can give explicit signals to guide the reader towards the intended interpretation of the text. Most of the students' essays achieve coherence because the total tokens of students' essays enter more than $50 \%$ of chain interaction. Only essay 3 is less coherent because the total tokens of essay 3 only achieve $47.87 \%$ of chain interaction. Essay 3 provides many cohesive devices but less coherence because the tokens of its cohesive devices do not interact with each other. Based on the study, it also can be concluded that the students overuse the type of repetition in creating the similarity chains. The overuse of certain cohesive devices by the students can lead to boredom to the readers and redundancy in their writing.

\section{REFERENCES}

Adiantika, H. N. (2015). Cohesive devices in EFL students' expository writing. Journal of English Education, 4(1), 94.

Amperawaty, A., \& Warsono. (2019). The use of cohesive devices to achieve coherence in the background section of the students' formal writing. English Education Journal, 9(1), 34-40.

Chiaoi, T. (2019). Coherence and cohesive harmony in filmic text. Journal of Chemical Information and Modeling, 53(9), 1689-1699.

Demantik, M. (2008). A cohesive harmony of reader's letters column Iin "Time " and " The Jakarta Post." Leksika, 2(2), 32-44.

Dontcheva-Navratilov, O. (2012). Coherence and cohesion in research article: The role of indexicals. Masarykova universita.

Eggins, S. (2004). An introduction to Halliday's systemic functional linguistics. Continuum.

Fitriati, S. W., \& Yonata, F. (2017). Examining text coherence in graduate students of English argumentative writing: Case study. Arab World English Journal, 8(3), 251-264.

Halliday, M. A. ., \& Hasan, R. (1989). Language, context, and text aspects of language in a socialsemiotic perspective. Routledge.

Halliday, M. A. K., \& Hasan, R. (1976). Cohesion in English. Longman.

Halliday, M. A. K., \& Matthiessen, C. M. I. M. (2014). Halliday 's introduction to functional grammar. Routledge.

Hasan, R. (1984). Understanding reading comprehension. Routledge.

Hellalet, N. (2013). Textual coherence in EFL student writing. IOSR Journal Of 
Humanities And Social Science, 15(3), 5458.

Hinkel, E. (2001). Matters of cohesion in L2 academic texts. Applied Laguage Learning, 12(2), 111-132.

Kafes, H. (2012). Lexical cohesion: An issue only in the foreign language? English Language Teaching, 5(3), 83-94.

Karadeniz, A. (2017). Cohesion and coherence in written texts of students of faculty of education. Journal of Education and Training Studies, 5(2), 93.

Khunaifi, A. R. (2015). The effects of teaching critical thinking on students' argumentative essay. Journal on English as a Foreign Language, 5(1), 45.

Lie, C. (2019). an online assesment approach to support mind mapping flipped learning activities for collage English wrating course. J. Comput Educ, 12(2), 385-415.

Lee, J. (2018). Cohesive harmony analysis for Ancient Greek: Selpap I:112 and Pmich Viii:491 as a test case. Biblical and Ancient Greek Linguistics, 7, 81-106.

Navratilova, O., Jancarikova, R., Missikova, G., \& Povolna, R. (2017). Coherence and cohesion in English discourse. Masaryk University.

Qudah, M. (2016). The use of lexical devices in political discourse. International Journal of English Languange, Literature and Translation Studies, 3(1), 18-19.
Rahman, Z. A. A. A. (2013). The use of cohesive devices in descriptive writing by Omani student-teachers. SAGE Open, 3(4).

Saud, W. I. (2015). Cohesion in the descriptive writing of EFL undergraduates. International Journal of Humanities and Cultural Studies, 2(2), 440-450.

Shabani, M., Tous, M. D., \& Berehlia, L. (2015). An investigation into the use of cohesive devises in iranian high school EFL textbooks. International Journal of Applied Linguistics and English Literature, 4(4), 36-45.

Somasundaran, S., Burstein, J., \& Chodorow, M. (2014). Lexical chaining for measuring discourse coherence quality in test-Taker essays. The 25th International Conference on Computational Linguistics, Proceedings of COLING , 950-961.

Suwandi. (2016). Coherence and cohesion: An analysis of the final project abstracts of the undergraduate students of PGRI Semarang. Indonesian Journal of Applied Linguistics, 5(2), 253-261.

Taboada, M. (2019). Cohesion and conjunction. The Cambridge Handbook of Systemic Functional Linguistics, 2, 311-332.

Tilney, M. (2018). Cohesive harmony and theme in Peter Carey's 'The last days of a famous mime.' Language and Literature, 27(1), 320.

Widdowson, H. G. (2007). Discourse analysis. Oxford Univesity Press. 